\title{
Transformation from Local Universities to Application-oriented Universities in China: 4 Core Elements
}

\author{
Ye ZHANG* \\ Institute of Higher Education \\ Shanghai Polytechnic University \\ Shanghai, China \\ yezhang@sspu.edu.cn
}

\begin{abstract}
Nowadays, the transformation from local universities to application-oriented universities has become an important national development strategy. However, there are many problems in the process of transformation, which are mainly reflected in university orientation, teaching staff, university-enterprise cooperation, and evaluation system. To begin with, such universities should redefine their orientation in the transformation. In the next place, universities need classified management, while teaching staff need diversified development; the construction of double-qualified teachers also needs to be strengthened. Furthermore, universities should cooperate with enterprises, communities, social organizations and other social forces as the main body to promote the participation of application-oriented universities governance. Last but not the least, evaluation system should be also reestablished for application-oriented universities.
\end{abstract}

Keywords-local Universities; Application-oriented Universities; Transformation; Core Elements

\section{INTRODUCTION}

With the rapid development of China's economy, there is an increasing shortage of application-oriented talents in all walks of life. Especially, advanced manufacturing and intelligent manufacturing require both of higher quality workers and higher education to make corresponding adjustments. During the cultivation of undergraduates, the necessary share and proportion for the cultivation of application-oriented talents are reserved. Therefore, the transformation of some local universities to applicationoriented universities is the only way.

In 2015, the Ministry of Education, the National Development and Reform Commission, and the Ministry of Finance jointly issued the "Guiding Opinions on Guiding Some Local Universities to Transform to Application-oriented Universities", pointing out the need to promote and speed up the transformation of some local universities. Under the background of the new round of education reforms, local universities need to adapt to the urgent needs of high-level applied talents in the upgrading of the country's industrial structure and the development of emerging industries, and transform toward the direction of applied technology,

This research was financially supported by the Young Research Foundation of the Ministry of Education, the 13th Five-year Plan of National Science of Education (Grant No. EJA170451) in China. highlighting the characteristics of education and building Core competitiveness. "Transform to Application-oriented universities" does not refer to the change of the name of the university, or to the upgrading of higher vocational education to undergraduate education, but to the transformation of the core elements of local universities. The transformation and development involve all aspects and is a comprehensive and systematic reform.

At present, many local universities have achieved certain successful experience in transformation. However, based on the related research and practice, there is still a lack of indepth research and exploration on issues such as "why transformation" and "how to transform". How to solve these problems has become an urgent task facing the current undergraduate education in China. In view of this, the local universities in the process of transformation to the applicationoriented universities, we should seize the following elements: transformation of university orientation, transformation of teaching staff construction, transformation of universityenterprise cooperation, and evaluation system transformation.

\section{TRANSFORMATION OF UNIVERSITY ORIENTATION}

In the process of transformation of local universities, the most important issue facing them is to re-define the university orientation. Many local universities cannot accurately grasp the development direction of the university when they redefine the university orientation [1]. For example, some universities have positioned education as a higher-educational version of higher vocational education. Cultivation models and teaching methods are similar to those of higher vocational education. Some universities copied the experience of other local universities and shout slogans instead of truly transforming themselves. Some universities did not fully consider its own conditions, blindly imitating the model of running a research university, and training academic talents rather than training applied talents. The unclear university orientation led some local universities to neglect their own advantages in the process of transformation and overemphasized the large-scale discipline construction.

The International Standard Classification of Education (2011) points out that the higher education system includes 
both academic education and advanced vocational or professional education. The system covers 5, 6, 7, and 8 levels, referring to short-term higher education (equivalent to China's higher vocational education), undergraduate or equivalent education, master's or equivalent education, doctoral or equivalent education. Level 6 higher education refers to providing students with a certain degree of professional knowledge and ability, usually based on theoretical knowledge, but also includes practical knowledge, high-level research and professional practice. Level 6 higher education has two orientation categories, academic and professional. It can thus be seen that the original orientation of the local universities is in line with the academic orientation of the 6th level of higher education, but after transformation, the university orientation should be adjusted to the professional orientation category, that is, application-oriented undergraduate education.

\section{TRANSFORMATION OF TEACHING STAFF CONSTRUCTION}

At present, there are still many problems in the construction of "dual-qualified" teachers in China's application-oriented universities. For example, the structure of teacher sources is single, the proportion of "dual-qualified" teachers is relatively low; the teacher training mechanism is not perfect, and the quality of "dual-qualified" teachers is overall low; the qualification standards for "dual-qualified" teachers are not yet clear, and they are temporarily lacking a feasible assessment mechanism; lack of an effective circulation mechanism between enterprises and universities, lack of a high-qualified part-time teaching staff; evaluation and incentive mechanisms are not perfect, and teachers are less active in entering corporate practice. Therefore, it is necessary to carry out the transformation from three aspects: the classification management of universities, the diversification of the teaching staff, and the construction of the "dual-qualified” teaching staff.

\section{A. Classification Management of Universities}

Universities are classified in many ways in China, ranging from new and old labels such as "985", "211" and even "double first-rate", to the distinction between academic-type and professional-type. No matter what kind of classification method is based on factors such as the level of education in universities and the orientation of talent cultivation, etc. Therefore, China should clarify the cultivation orientation of various types of universities. It should establish management plans for different types of universities and formulate assessment rules separately. In particular, for applicationoriented universities, teachers should not only have scientific research ability and teaching ability, but also have practical ability or industry work experience. In this way, we can ensure that teachers do not teach too much theoretical knowledge in the teaching process. Instead, they can incorporate the latest and most practical knowledge into the teaching content and teaching methods.

\section{B. Diversification of the Teaching Staff}

For the application-oriented universities, part of the technical staff from outside can be recruited in the teaching staff. It could make the teaching staff more diverse.
Diversification will bring about the differentiation of teacher types. Therefore, it is necessary to provide different types of teachers with development paths and realize their talents. The appraisal system for teacher title in applied universities should be focused on, and distinct from research universities: more attention should be paid to the ability of teachers to develop new technologies and processes, evaluate the ownership of patents, and establish a balance between academic standards and skill levels in the evaluation system. Experts participating in the review should come from enterprise and applicationoriented universities, thus making the entire evaluation process more reasonable, objective and targeted [2].

\section{Construction of the "Dual-qualified" Teaching Staff}

From the perspective of the "dual-qualified" teacher training strategy, we should base on the basic standards and professional classification standards to build a "dual-qualified" teacher qualification certification standard system; focus on strengthening professional capabilities, improve the training mechanism; build a "dual-qualified" teachers' evaluation mechanism; establishment of "dual-qualified" teacher professional development promotion and incentive mechanism.

From the perspective of the "dual-qualified" teacher construction strategy, it is necessary to improve the structure of the teaching staff; strengthen university-enterprise cooperation and establish a part-time teacher talent pool; improve the employment system of part-time teachers; and strengthen the training of Part-time Teachers' Teaching ability and practical ability and give full play to the complementary role of Part-time Teachers.

\section{TRANSFORMATION OF UNIVERSITY-ENTERPRISE COOPERATION}

The transformation of university-enterprise cooperation is the key element for the transformation of local universities to application-oriented universities. Local universities have their own distinctive regional characteristics in running universities. In the process of transformation, they can strengthen professional development and application-oriented personnel training in accordance with the needs of industrial development in various localities, thereby serving the local economy. However, in the process of actual transformation, many local universities lack understanding of local economic development status and industrial policies, lack of communication and cooperation with local enterprises. University-enterprise cooperation is also formalistic and superficial. In addition, in the actual implementation of university-enterprise cooperation, there are many problems. For example, the enthusiasm of the enterprises to participate is not high enough, the roles of the university and the enterprise are not clearly defined, etc. The university-enterprise cooperation is too formal, and the emphasis is placed on the quantity rather than the quality of the cooperative enterprises. The stability is not enough, and the willingness of enterprises to cooperate is not strong. Most of the cooperative enterprises are mostly small and medium-sized enterprises, and the enterprises do not have enough human and material resources to participate in university-enterprise cooperation. As a result, these universities are unable to cultivate applied talents 
adapted to the needs of local industry development on the one hand, and on the other hand are unable to serve the local economy and industrial development very well, thus making it difficult to obtain the support of local governments and enterprises [3].

The "Guiding Opinions on Guiding Some Local Universities to Transform to Application-oriented Universities" points out that it is necessary to "establish a cooperative education and cooperative governance mechanism in which universities, localities, industries, enterprises, and communities participate together". Therefore, taking social forces such as corporations, communities, and social organizations as the main body and promoting participation in the Governance of application-oriented universities is the only way for them to move toward transformation and development [4].

\section{TRANSFORMATION OF EVALUATION SYSTEM}

The evaluation system of the current local universities has undergone many reforms, but there are still many problems. For example, under the background of the popularization of higher education, some universities lack a clear understanding of their own development positioning. They cannot adapt to the market demand under the transformation of economic development, and do not adjust the objectives of talent cultivation in a timely manner. They lack attention to the need for individual growth and development, which, to a certain extent, restricts the growth of advanced applied talents [5].

With the introduction of Howard Gardner's theory of multiple intelligences in 1983 and its full application in educational practice, multiple evaluation came into being. Gardner argues that there is no question of who is smart or who is not, but of which and how smart. This concept points out that the content, subject, form and standard of educational evaluation should all be diversified. Therefore, to carry out the research on the transformation of the evaluation system of local universities, to construct a new multi-evaluation system of local universities, which is more scientific, reasonable, operable and effective, to promote the growth of students and the development of teachers, to improve the teaching quality of universities should be an important task in the transformation from local universities to application-oriented universities [6].

\section{A. Evaluation Content}

Evaluation content should be diversified. In the past, the evaluation content of local universities focused on the evaluation of knowledge and skills. Nowadays, the transformation of such universities to application-oriented universities requires a broader coverage of theoretical and practical knowledge to be taught and examined. It is necessary to continuously add the latest and practically relevant knowledge to the evaluation content. The depth of theoretical knowledge should be further deepened. We should pay attention to the cultivation of students' professional ability, application ability and cooperation ability. Besides, we should also mention non-intelligence factors such as interests and emotions, will and values, and professional knowledge and capabilities at the same important levels.

\section{B. Evaluation Subject}

Evaluation subject of application-oriented universities should be diversified, including students, teachers, administrators and experts of enterprise. The self-evaluation, peer review and third-party evaluation are the main forms and form a diversified evaluation system. The so-called diversification means that the angle of evaluation of educational activities is more diverse, which makes the evaluation result comprehensive and objective. This requires that the evaluation objects in the traditional evaluation system-students and teachers - change their roles, take the initiative to participate in the evaluation, reflect their main status, and achieve self-examination and improvement.

\section{Evaluation Form}

The form of evaluation is mainly reflected in the reforms of assessment and examination methods and the diversity of evaluation methods. It is necessary to diversify the forms of evaluation. Should be based on the teaching requirements of different courses, combined with the purpose of the examination, flexible choice of test form. The students' knowledge level and practical application ability can be fully examined in the form of oral exams, written exams, research reports, thesis, or completing a project. Each evaluation form should have a certain weight to comprehensively evaluate student performance. In addition, a combination of quantitative evaluation and qualitative evaluation should also be adopted, focusing on people-oriented, humane care, and the objectivity of the evaluation process and evaluation results.

\section{Evaluation Standard}

Application-oriented universities should adhere to the evaluation criteria of scientific, objective, comprehensive and diversity. It is necessary to fully consider factors such as regional differences, university-level differences, student characteristics, talent cultivation goals and other factors. These universities should also take into account the different teachers' teaching style, teaching experience, personality characteristics to carry out diversified evaluation. The combination of quantitative indicators and qualitative indicators should be used to evaluate the overall quality of students [7]. When designing teaching quality evaluation, we should insist on both the diversity of forms and the accuracy of connotation. Based on multidimensional teaching activities, we should pay more attention to the rating system and the incentive scoring system in assessment.

\section{CONCLUSION}

Application-oriented undergraduate education is the product of the popularization of higher education, which is relative to research undergraduate education or academic undergraduate education. Instead of imparting professional skills, application-oriented universities emphasize the importance of theoretical knowledge and professional practice equally, besides, pay more attention to the application and transformation of knowledge and skills. Therefore, the 
application-oriented undergraduate education is not a simple extension of vocational education, its connotation is more profound. It is not easy to truly realize the transformation of some local universities to application-oriented universities. Roads to transform involves not only the understanding of the government, universities, enterprises and markets, but also the reform of the policy level. It also requires the active transformation and practice of the relevant applicationoriented universities in terms of university orientation, teaching staff, university-enterprise cooperation and evaluation systems.

\section{ACKNOWLEDGMENT}

The author would like to extend his gratitude to the foundation and Shanghai Polytechnic University. Thanks also go to the anonymous reviewers for their invaluable comments. All the remaining faults are the author's.

\section{REFERENCES}

[1] Z. J. Wu, C. L. Huang. "Connotation of Applied Talents and Cultivation of Application-oriented Undergraduate Talents,” Research in Higher Education of Engineering, 2014, (02), pp. 66-70. (In Chinese)

[2] H. H. Yan, G. Q. Xu. "Challenges and Strategies of Construction of Teaching staff for Application-oriented Universities,” Vocational \& Technical Education Forum, 2016, (26), pp. 12-16. (In Chinese)

[3] J. G. Wang, J. Sun. “On the Essential Attribute and Development Key of Application-oriented Universities-Based on the Background of the Transformation of Local Universities," Heilongjiang Researches on Higher Education, 2016(03), pp. 33-37. (In Chinese)

[4] N. Shao. "Social Involvement in the Governance of American Community Colleges and Its Enlightenment to the Governance of China's Application-oriented Universities,” Vocational \& Technical Education Forum, 2016, (24), pp. 92-96. (In Chinese)

[5] Y. Zhang. "A Dual Study Model for China," The Vocational School, 2016, 68( 5), pp. 185-187. (In German)

[6] M. Gao. "Connotation, Development Basis and Realization Model of Application-oriented Undergraduate Education," Education and Vocation, 2016, (14), pp. 12-15. (In Chinese)

[7] Y. Zhang. The Study Model at the Dual University in Germany and Its Adaptation in China. Hamburg: Dr. Kovac Press, 2016. (In German) 